Check for updates

Cite this: RSC Adv., 2017, 7, 22567

\title{
Facile synthesis of mesoporous graphene platelets with in situ nitrogen and sulfur doping for lithium- sulfur batteries $\uparrow$
}

\author{
Xiqing Yuan, ${ }^{a}$ Bingchuan Liu, ${ }^{a}$ Huijie Hou, ${ }^{a}$ Kemal Zeinu, ${ }^{a}$ Yuhang $\mathrm{He},{ }^{a}$ \\ Xiaorong Yang, ${ }^{a}$ Weijun Xue, ${ }^{a}$ Xiulin He, ${ }^{a}$ Long Huang, ${ }^{a}$ Xiaolei Zhu, ${ }^{a}$ Longsheng $\mathrm{Wu}^{a}$ \\ Jingping $\mathrm{Hu}$, (D) *a Jiakuan Yang (DD) and Jia Xie ${ }^{\mathrm{b}}$
}

\begin{abstract}
The interaction between lithium polysulfides and doped heteroatoms could prevent the loss of soluble polysulfides in the cathode and mitigate the shuttle effect in lithium-sulfur batteries. Herein, a facile synthesis of mesoporous graphene platelets (NSGs) with in situ nitrogen and sulfur doping by the pyrolysis of a self-assembled L-cysteine precursor on sodium chloride crystal surface for structuredirecting is presented. The mesoporous lamellar structure of the NSG possesses a uniform distribution of pyrrolic $\mathrm{N}$, pyridinic $\mathrm{N}$, and thiosulphate structured heteroatoms originating from in situ doping, which promotes the confinement of intermediate polysulfides. Combining the strong interactions with soluble polysulfide, flexible mesoporous architecture, and high conductivity of graphene, the prepared NSG material exhibited a high initial capacity of $1433 \mathrm{~mA} \mathrm{~h} \mathrm{~g}^{-1}$ at a $2 \mathrm{C}$ rate as well as a reversible capacity of $684 \mathrm{~mA} \mathrm{~h} \mathrm{~g}^{-1}$ after 200 cycles. This demonstrates that the in situ nitrogen and sulfur doped thin lamellar structure of graphene would be a promising cathode material for high performance lithium-sulfur batteries.
\end{abstract}

Received 16th February 2017 Accepted 17th April 2017

DOI: 10.1039/c7ra01946g

rsc.li/rsc-advances and the shuttle effect. Among the carbon materials for $\mathrm{Li}-\mathrm{S}$ batteries, graphene is a promising candidate because of its high electron mobility, good chemical stability, and super hydrophobicity at nanometer scale. ${ }^{15-17}$ Graphene synthesized from chemical vapor deposition (CVD), ${ }^{18}$ electrolytic exfoliation of graphite ${ }^{19}$ and reduction of graphene oxide $\mathrm{e}^{20-22}$ has been utilized in $\mathrm{Li}-\mathrm{S}$ batteries. However, the current fabrication processes are complicated, time-consuming, and costly, which involved toxic chemicals and corrosive acid. Therefore, it is highly desired to develop a facile and green method to prepare novel porous graphene materials on an easily processed template with unique structure for enhanced electrochemical performance.

Besides the development of novel carbon structures, the introduction of polysulfide affinitive heteroatoms on carbon materials by doping has attracted much attention in the preparation of sulfur cathodes for $\mathrm{Li}-\mathrm{S}$ batteries ${ }^{23,24}$ by taking advantage of the strong attraction between lithium polysulfides and doped active sites on these carbon materials. ${ }^{25}$ Recently, silk fibroin protein had been used to produce porous nitrogendoped carbon material for Li-S batteries. ${ }^{26}$ The cathode had a capacity retention of $98 \%$ at $1 \mathrm{C}$ after 200 cycles, which was partially attributed to the nitrogen doping for the adsorption of polysulfides. Xie et al. prepared a boron-doped 3D graphene aerogel via a one-pot hydrothermal treatment process. ${ }^{27}$ The electrochemical performance improved considerably because boron was positively polarized on the graphene framework, providing chemical adsorption sites for negative polysulfides. 3D coral-like nitrogen-sulfur co-doped carbon was synthesized
${ }^{a}$ School of Environmental Science and Engineering, Huazhong University of Science and Technology (HUST), Wuhan, 430074, PR China. E-mail: hujp@hust.edu.cn; jkyang@hust.edu.cn; Fax: +86-27-87792101; Tel: +86-27-87793948

${ }^{b}$ School of Electrical \& Electronic Engineering, Huazhong University of Science and Technology (HUST), Wuhan, 430074, PR China

$\dagger$ Electronic supplementary information (ESI) available. See DOI: 10.1039/c7ra01946g 
by a novel hydrothermal-nanocasting method to house sulfur for Li-S batteries. ${ }^{28}$ The co-doping of nitrogen and sulfur enabled the carbon matrix to mitigate the diffusion of polysulfides. Therefore, it is believed that heterogeneous doping of carbon material can improve the electrochemical performance of $\mathrm{Li}-\mathrm{S}$ batteries through enhanced interaction between polar functional group and polysulfide. ${ }^{29-31}$ However, further progress is still imperative on the design and synthesis of novel carbon materials with regard to the following aspects: (i) homogeneous distribution of heteroatoms, ideally in situ doping from precursor during synthesis; (ii) a thin, flexible and very conductive mesoporous structure used for sulfur host with easily accessible pores for lithium ions and provided a facile electron pathway; (iii) an easily manageable template that can be processed at mild conditions.

In the present work, we synthesized nitrogen and sulfur doped graphene platelet (NSG) by in situ doping through a novel

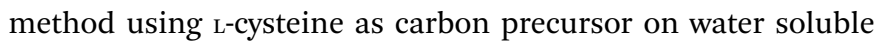
salt which acted as a template. L-Cysteine is rich in sulfur and nitrogen in the form of thiol and amine groups which can be easily polymerized with its carboxylic group. The carbon material is presumed to exhibit high electrical conductivity and abundant nitrogen and sulfur containing active sites. The electrochemical performance of the hybrid cathode was investigated, and the composite delivered a high rate capacity and excellent cycling stability for application in Li-S batteries.

\section{Experimental}

\section{Synthesis of N,S co-doped graphene platelet}

Typically, L-cysteine ( $1 \mathrm{~g})$ and $\mathrm{NaCl}$ (15 g) were added to deionized water $(200 \mathrm{~mL})$. After stirring for $12 \mathrm{~h}$, the solution was frozen in a refrigerator at $-28{ }^{\circ} \mathrm{C}$ for $48 \mathrm{~h}$. The solid mixture was then freeze-dried (FD-1-50 freeze dryer, Biocool, China) to remove water content. The dried Cys-NaCl mixture was ground to obtain a uniform powder, which was heated at $800{ }^{\circ} \mathrm{C}$ for $2 \mathrm{~h}$ with a heating rate of $5{ }^{\circ} \mathrm{C} \min ^{-1}$ in $\mathrm{N}_{2}$ gas (100 sccm flow rate) to produce Cys-NaCl-800 composites. Subsequently, the $\mathrm{NaCl}$ template was dissolved by rinsing with hot distilled water for several times. The obtained sample was further pyrolyzed at $1000{ }^{\circ} \mathrm{C}$ for $3 \mathrm{~h}$. After that, the final NSG (around $40 \mathrm{mg}$ ) was cooled down to room temperature and collected after grinding.

\section{Preparation of carbon-sulfur composites}

The N,S co-doped graphene platelet was mixed with sulfur in the mass ratio of $m_{\mathrm{S}}: m_{\mathrm{C}}=3: 1$. The mixture was sealed in a stainless steel container and kept at $155{ }^{\circ} \mathrm{C}$ for 12 hours to impregnate the pores with sulfur, followed by another heat treatment in a tube furnace at $300{ }^{\circ} \mathrm{C}$ for 2 hours under $\mathrm{N}_{2}$ atmosphere to remove excess sulfur on the carbon surface.

\section{Preparation of cathode}

The carbon-sulfur composite, super $\mathrm{P}$ carbon, and polyvinylidene fluoride $(80: 10: 10)$ were ground in a mortar for 40 minutes using $n$-methyl-2-pyrrolidinone as the solvent, then the slurry was coated on an $\mathrm{Al}$ foil, pressed tight with a roller machine and then polished with a blade. The foil was dried at $50{ }^{\circ} \mathrm{C}$ for 6 hours in a vacuum oven, and hand punched into disks of a diameter of $8 \mathrm{~mm}$. A sulfur loading of around $2.2 \mathrm{mg}$ $\mathrm{cm}^{-2}$ was used in all the experiments.

\section{Electrochemical measurements}

Lithium foil with a diameter of $16 \mathrm{~mm}$ was used as the anode, and a commercial polypropylene separator (Celgard 2400) was used as the separator. A mixture of $1 \mathrm{M}$ lithium bistrifluoromethanesulfonylimide (LiTFSI) and $0.2 \mathrm{M} \mathrm{LiNO}_{3}$ dissolved in 1,3-dioxolane (DOL) and 1,2-dimethoxyethane (DME) ( $1: 1$ by volume) was used as the electrolyte. Electrolyte of $90 \mu \mathrm{L}$ for a cell was used to infiltrate the positive cathode fully during the fabrication. Coin cells (2032) were fabricated in an argonfilled glove box and cycled between 2.8 and $1.7 \mathrm{~V}\left(v s . \mathrm{Li}^{+} / \mathrm{Li}\right)$ at $26^{\circ} \mathrm{C}$ using a battery test system (LAND CT2001A, China). Cyclic voltammetry $(\mathrm{CV})$ was carried out by potential cycling between $3 \mathrm{~V}$ and $1.5 \mathrm{~V}$ with a sweeping rate of $0.2 \mathrm{mV} \mathrm{s}^{-1}$, and electrochemical impedance spectroscopy (EIS) measurement was conducted in the frequency range of $100 \mathrm{kHz}$ to $100 \mathrm{mHz}$ with an $\mathrm{AC}$ amplitude of $5 \mathrm{mV}$ using an electrochemical workstation (Biologic, VSP 300, France).

\section{Characterizations}

Scanning electron microscopy (SEM) measurements were performed using FEI Nova NanoSEM 450 operated at an acceleration voltage of $10 \mathrm{kV}$ after coating the samples with a very thin layer of gold to eliminate charging effect, and energy dispersive X-ray spectroscopy (EDX) spectra were acquired at an acceleration voltage of $20 \mathrm{kV}$. Transmission electron microscopy (TEM) images were acquired using Tecnai G2 F30 (Netherlands). BrunauerEmmett-Teller (BET) type nitrogen adsorption isotherm measurements were conducted using automatic specific surface area and porosity analyzer (JW-BK122W, JWGB LTD., China). The crystalline structure was identified by X-ray diffraction analysis (XRD, D/MAX 2550, Rigaku, Japan) using $\mathrm{Cu} \mathrm{K} \alpha$ radiation $(\lambda=$ $1.54 \AA$ ), with an operation voltage of $40 \mathrm{kV}$ and current of $300 \mathrm{~mA}$. Thermal gravity analysis (TGA) was performed using TA SDT Q600, with a heating rate of $10{ }^{\circ} \mathrm{C} \mathrm{min}^{-1}$. Raman measurements were performed using a Jobin Yvon LabRAM HR800, excited by a $632.8 \mathrm{~nm}$ He-Ne laser. X-ray photoelectron spectroscopy (XPS) measurements (GENESIS, American) were performed to analyze the surface chemistry of the material, and analyzed quantitatively using CasaXPS software.

\section{Computational details}

The simulation was conducted using $\mathrm{Dmol}^{3}$ package in Materials Studio 8.0 software. Geometry optimization calculations were performed under the generalized gradient approximation (GGA) using the Perdew-Burke-Ernzerhof (PBE) exchangecorrelation function. A double numerical basis with polarization (DNP) as well as effective core potential (ECP) were adopted for a large supercell $(5 \times 5)$ of graphene, and the self-consistent field tolerance was set to $10^{-5} \mathrm{Ha}$. 


\section{Results and discussion}

The synthesis of N,S co-doped graphene platelet was carried out by pyrolysizing L-cysteine on $\mathrm{NaCl}$ crystal template (Scheme 1). After freeze-drying, cysteine molecules were assembled on $\mathrm{NaCl}$ crystal surface, which acted as a template for the subsequent formation of 2D carbon structure. During pyrolysis, the assembled cysteine was polymerized, aromatized and carbonized on the surface of $\mathrm{NaCl}$ crystals, followed by washing off the $\mathrm{NaCl}$ template and a further pyrolysis at high temperature to obtain graphene platelet.

The produced graphene platelet material using a $\mathrm{NaCl}$ template exhibited an entangled sheet-like morphology as shown in SEM and TEM images in Fig. 1a and c. TEM results showed that the NSG was very thin and exhibited typical corrugated structure (Fig. 1c), which was beneficial for the enhanced performance of Li-S batteries. ${ }^{32-34}$ From the EDX results (Fig. 1b), the presence of $\mathrm{C}, \mathrm{O}, \mathrm{N}$, and $\mathrm{S}$ can be observed, together with a weak Au signal originated from the sample pretreatment. The sodium or chloride signal was not discernible in the EDX spectrum, indicating the complete removal of $\mathrm{NaCl}$ template by simply rinsing with water during synthesis. EDX mapping revealed that the NSG was doped with $\mathrm{N}$ and $\mathrm{S}$ elements, and nitrogen and sulfur were not homogeneously distributed (Fig. 2d-g). The mild processing condition was beneficial to mitigate excess defects introduced in the honeycomb structure of graphene, considering that the lots of defects were detrimental to the electrical conductivity. The atomic contents of nitrogen and sulfur were almost identical, in agreement with the stoichiometry of thiol and amine groups in L-cysteine $\left(\mathrm{HO}_{2} \mathrm{CCH}\left(\mathrm{NH}_{2}\right) \mathrm{CH}_{2} \mathrm{SH}\right)$, implying that $\mathrm{N}$ and $\mathrm{S}$ elements were successfully doped in the NSG. The in situ nitrogen and sulfur co-doping was derived from the polycondensation reaction between thiol and amine groups and between carboxylic group and amine groups of L-cysteine during pyrolysis, leading to the formation of some residual $\mathrm{C}-\mathrm{S}$ and $\mathrm{C}-\mathrm{N}$ bonds in the graphene framework that partially survived from the pyrolysis treatment.

After a facile melting-diffusion and infiltration treatment, the composite of NSG and sulfur was obtained as shown in the SEM and TEM images (Fig. 2). No discernible morphology changes were observed after loading with sulfur and further heat treatment at $300{ }^{\circ} \mathrm{C}$, indicating no excess sulfur debris at the exterior surface of NSG (Fig. 2a). EDX mapping revealed that the NSG/S composite was doped with $\mathrm{N}$ and $\mathrm{S}$ elements, and nitrogen and sulfur were homogeneously distributed throughout the NSG/S composite (Fig. 2d-g). The uniform distribution of $\mathrm{N}$ and $\mathrm{S}$ could be attributed to the inherent origination of dopant from the L-cysteine precursor. Sulfur was uniformly distributed inside the pores, which can be confirmed by the TEM images in Fig. 2c. The well dispersion of sulfur inside the mesopores of NSG was critical for improving the performance of $\mathrm{Li}-\mathrm{S}$ batteries. ${ }^{35-37}$

The $\mathrm{N}_{2}$ adsorption-desorption isotherms, pore size distribution and the total pore volume curves of the NSG and NSG/S composite were derived from BET measurements to validate the presence of mesopores in the materials (Fig. 3a-d). After sulfur incorporation in NSG, the BET surface area of NSG $\left(450 \mathrm{~m}^{2} \mathrm{~g}^{-1}\right)$ decreased to $28 \mathrm{~m}^{2} \mathrm{~g}^{-1}$, and the total pore volume of NSG/S composite also decreased from $3.6 \mathrm{~cm}^{3} \mathrm{~g}^{-1}$ to $0.24 \mathrm{~cm}^{3} \mathrm{~g}^{-1}$, indicating that the sulfur was infused into the pores of NSG. The high surface area of NSG was attributed to the assembling of 2D graphene structure on the $\mathrm{NaCl}$ crystal template, which produced very thin and wrinkled layers with abundant pores.
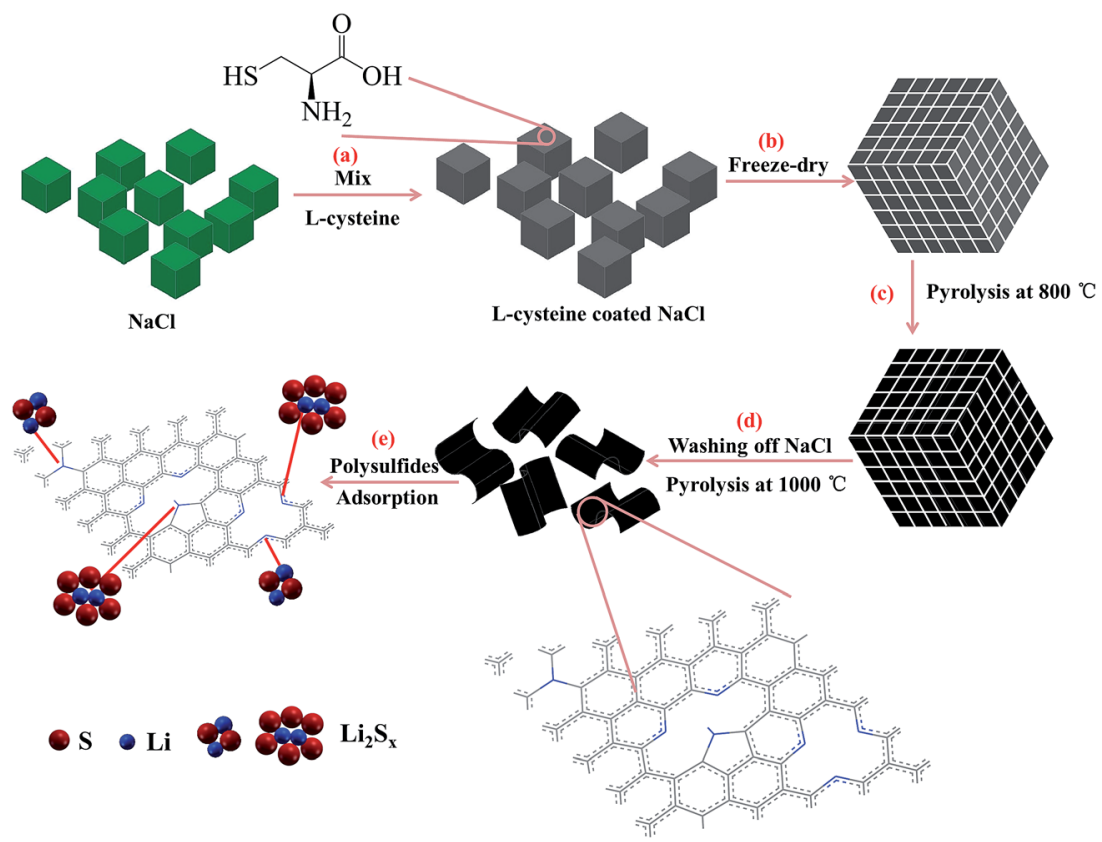

Scheme 1 (a)-(d) Schematic illustration of the synthesis process of graphene platelet and the mechanism for in situ doping with nitrogen and sulfur, and (e) adsorption of polysulfides on the graphene platelet. 

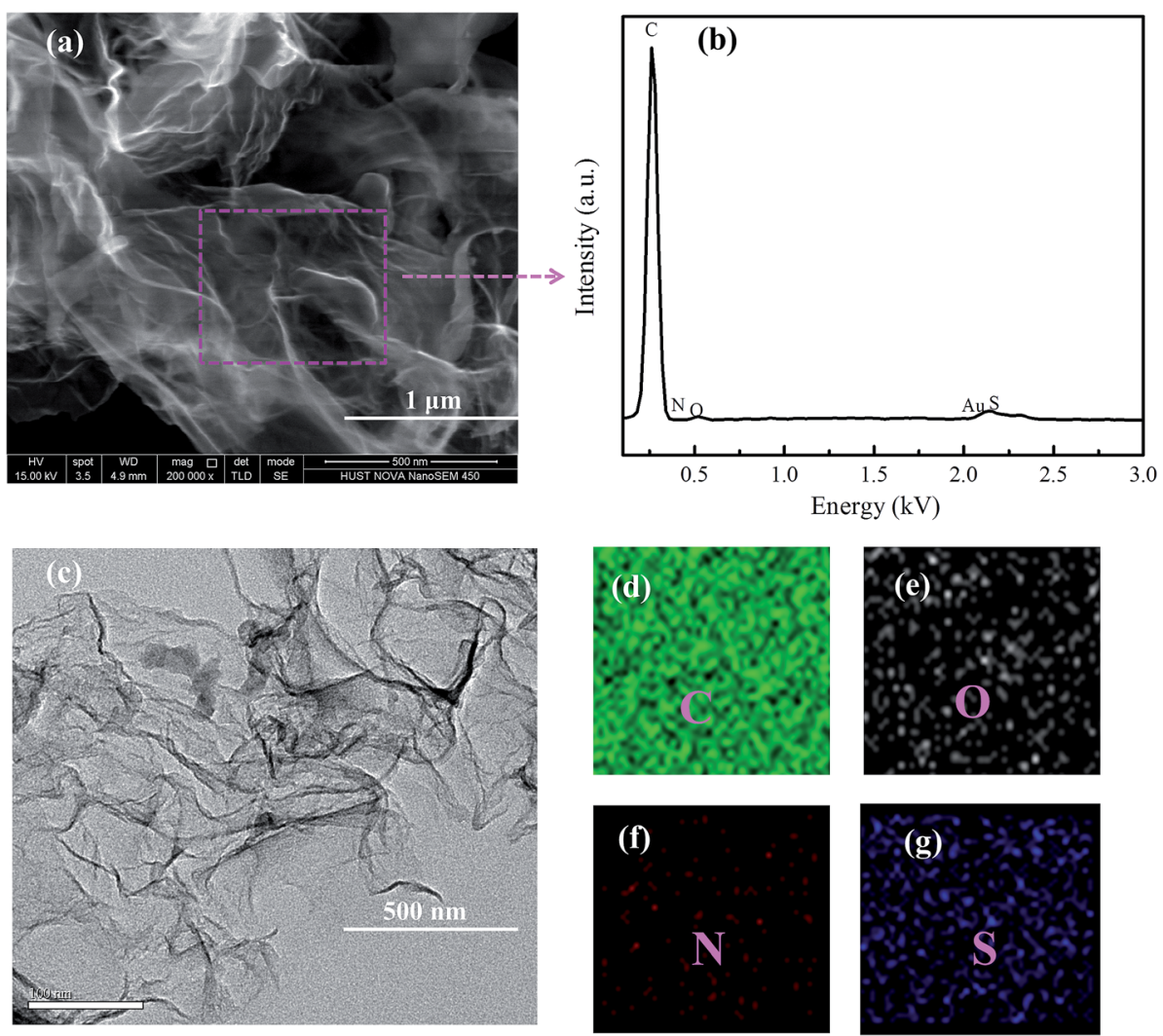

Fig. 1 (a) and (c) SEM and TEM images of NSG, (b) elemental analysis, (d) C, (e) O, (f) N and (g) S elemental mapping of the selected region by EDX.
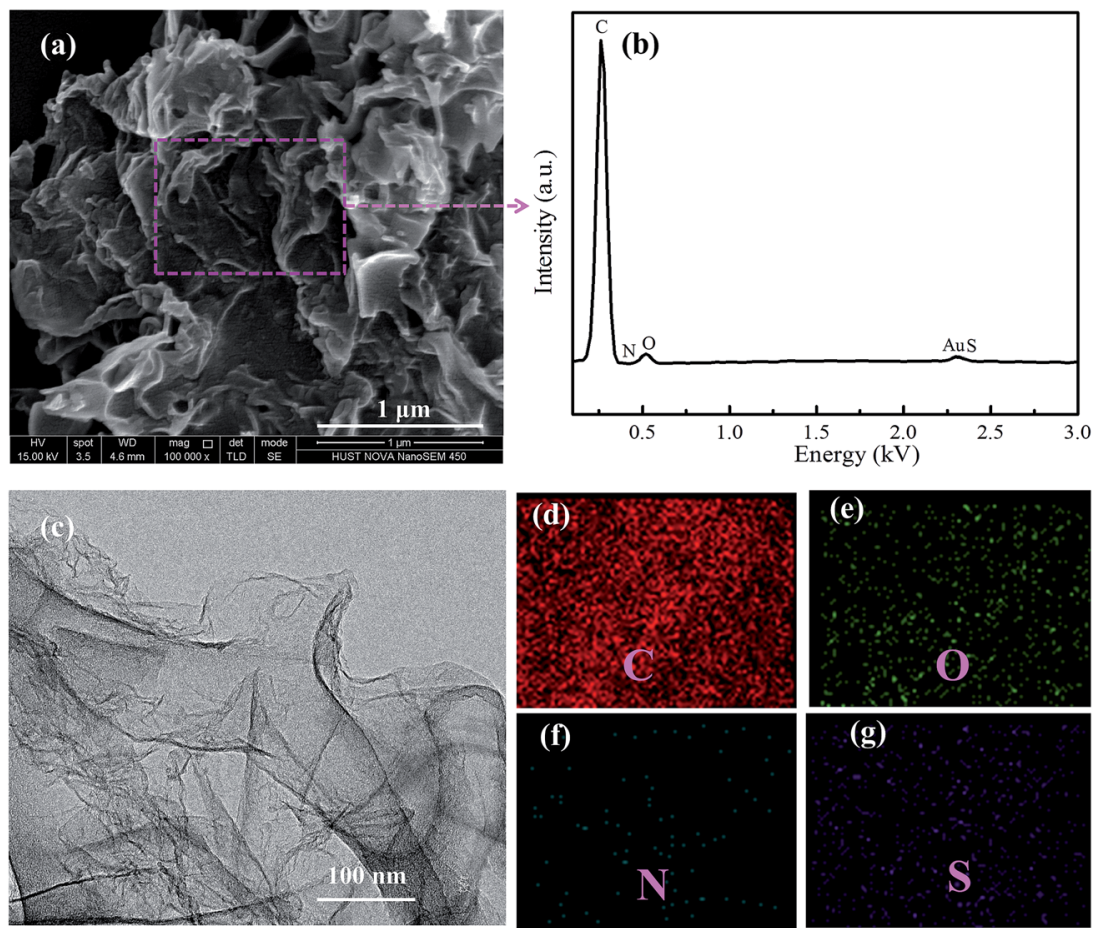

Fig. 2 (a) and (c) SEM and TEM images of the NSG/S composite, (b) elemental analysis, (d) C, (e) O, (f) N and (g) S elemental mapping of the selected region by EDX. 

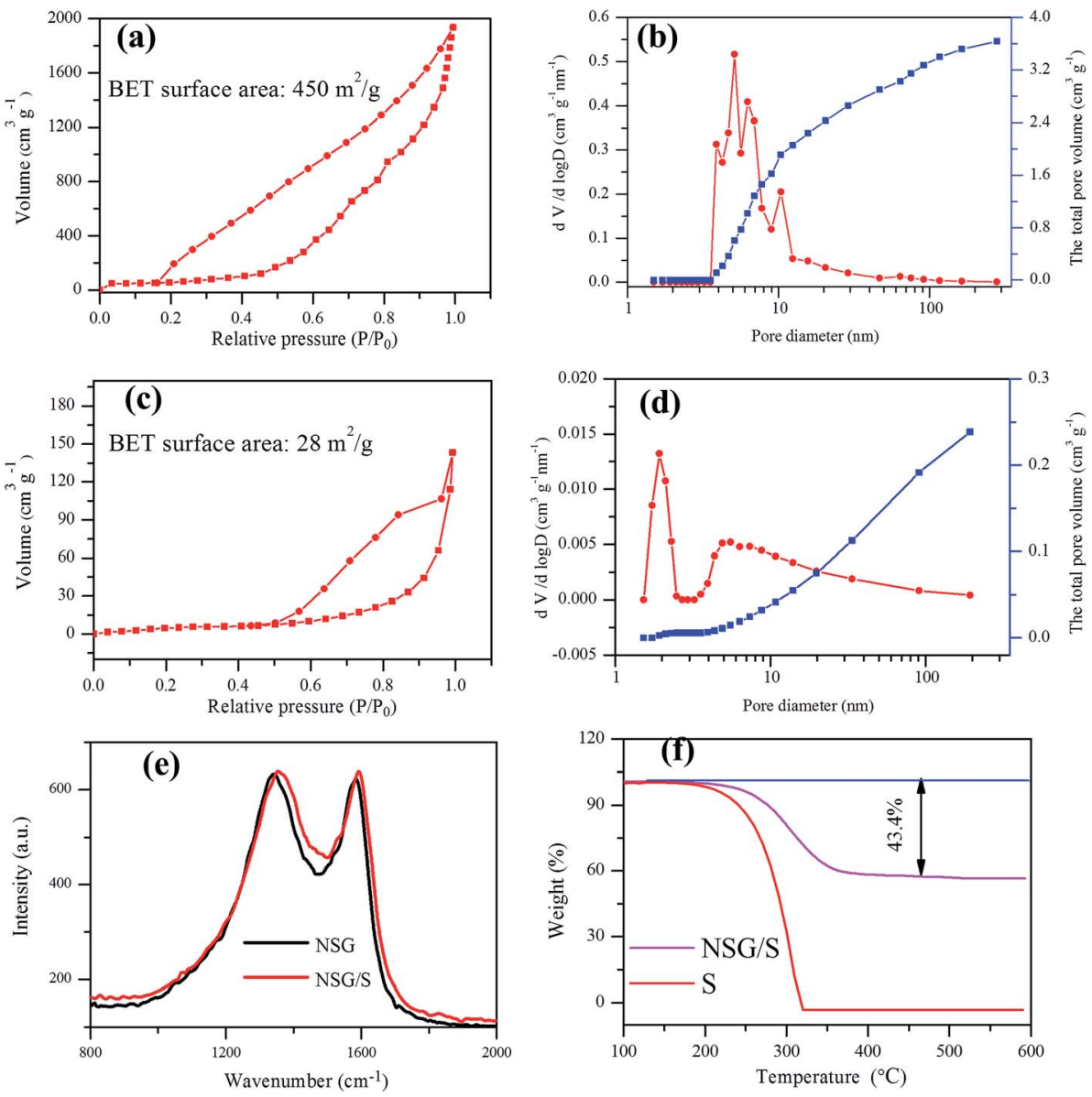

Fig. $3 \mathrm{~N}_{2}$ adsorption-desorption isotherm plot of (a) NSG, (b) NSG/S composite; BJH pore size distribution and total pore volume of (c) NSG, (d) NSG/S composite; Raman spectra of (e) NSG and NSG/S mixture, and TGA results of (f) elemental sulfur and the NSG/S mixture.

However, the surface area of NSG was much lower than the theoretical value of single-layered graphene, ${ }^{\mathbf{3 8}}$ probably due to the few-layered structure and stacking of interlayers induced by strong $\pi-\pi$ interaction.

The degree of graphitization of the NSG and the NSG/S mixture was evaluated using Raman spectroscopy (Fig. 3e). The $I_{\mathrm{D}} / I_{\mathrm{G}}$ ratio of the NSG was 1.019 , suggesting the presence of defects in NSG and a sufficient degree of graphitization for high electrical conductivity ${ }^{39,40}$ which was especially beneficial to retain a high rate capacity. After the infusion of sulfur, the $I_{\mathrm{D}} / I_{\mathrm{G}}$ ratio in Raman spectra decreased slightly to 1.003 , indicating little change in microstructure during sulfur encapsulation, which was beneficial for the stability of batteries. In the meantime, the weight content of sulfur in the NSG/S composite was evaluated by TGA (Fig. 3f) and the sulfur loading in the NSG/S mixture was estimated to be $43.4 \%$, which was adopted for the calculation of battery capacities.

The crystal structures of NSG, sulfur and the NSG/S mixture were analyzed using XRD (Fig. 4). The XRD spectra of NSG exhibits a broad diffraction peak at $25^{\circ}$ (Fig. 4a) which can be associated with partially graphitized carbon. ${ }^{\mathbf{4 1}}$ After encapsulation of sulfur inside the pores of mesoporous sheets, the sulfur peaks became much weaker (Fig. 4c), confirming the incorporation of well dispersed sulfur inside the pores.
The charge-discharge test of assembled Li-S battery was carried out to evaluate the electrochemical performance of this NSG/S composite, as shown in Fig. 5. From the chargedischarge profiles of the batteries (Fig. $5 \mathrm{a}-\mathrm{c}$ ), it can be observed that the discharge capacity of the first cycle at $0.5 \mathrm{C}, 1 \mathrm{C}$ and $2 \mathrm{C}$ are $1603 \mathrm{~mA} \mathrm{~h} \mathrm{~g}^{-1}, 1635 \mathrm{~mA} \mathrm{~h} \mathrm{~g}^{-1}$, and $1433 \mathrm{~mA} \mathrm{~h} \mathrm{~g}$

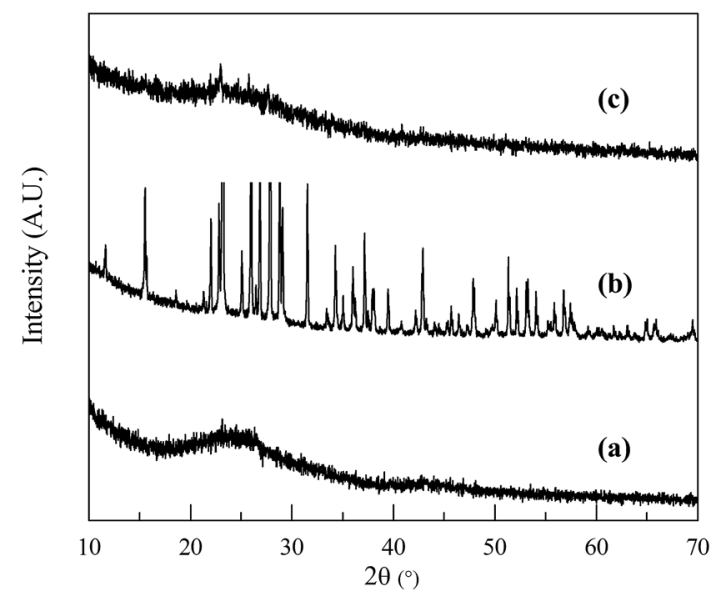

Fig. 4 XRD patterns of (a) NSG, (b) sulfur and (c) the NSG/S mixture. 
respectively, and the cathode convertible capacity retained at $889 \mathrm{~mA} \mathrm{~h} \mathrm{~g}^{-1}, 803 \mathrm{~mA} \mathrm{~h} \mathrm{~g}^{-1}$ and $716 \mathrm{~mA} \mathrm{~h} \mathrm{~g}^{-1}$ after 100 cycles, implying a good cycling stability of the batteries at high current rate (2C). The discharge capacity of the first cycle at $0.5 \mathrm{C}$ slightly lower than that of the result at $1 \mathrm{C}$ is most likely attributable to different sulfur loadings, $2.25 \mathrm{mg} \mathrm{cm} \mathrm{cm}^{-2}$ and $2.11 \mathrm{mg} \mathrm{cm}^{-2}$ respectively. As we all know, the electrochemical performance of the batteries deteriorated with the increasing sulfur loading in the $\mathrm{Li}-\mathrm{S}$ batteries due to the increased concentration polarization of polysulfides in the cathode..$^{42}$ It is apparent that there are two discharge plateaus and a single charge plateau, corresponding to the peaks in the cyclic voltammogram. The two discharge plateaus were related to the reduction peaks and the charge plateau was related to the oxidation peak. Meanwhile, these two plateaus in the discharge curves maintained almost the same potential during all cycles at $2 \mathrm{C}$ rate, implying stable charge transfer kinetics at the electrode-electrolyte interface during charge and discharge process even at fairly high rate current. $^{21}$ The charge-discharge potential difference $(\Delta E)$ of the batteries also remained almost constant with increasing cycle numbers, indicating excellent cycle reversibility of these batteries.

The cycle stability tests at $0.5 \mathrm{C}, 1 \mathrm{C}$ and $2 \mathrm{C}$ are compared in Fig. 5d-f. After 200 cycles, the batteries delivered a reversible capacity of $754 \mathrm{~mA} \mathrm{~h} \mathrm{~g}^{-1}, 711 \mathrm{~mA} \mathrm{~h} \mathrm{~g}^{-1}$, and $684 \mathrm{~mA} \mathrm{~h} \mathrm{~g}^{-1}$ with $47.0 \%, 44.4 \%$, and $47.7 \%$ capacity retention, implying a capacity loss of $0.24 \%, 0.22 \%$, and $0.24 \%$ per cycle, respectively. The capacity value revealed that the batteries retained excellent cycle stability especially at high current rate. When the current rate increased from $0.5 \mathrm{C}$ to $2 \mathrm{C}$, the cycle stability of the batteries didn't deteriorate so much, implying a high rate stability of the NSG/S composite, which can be attributed to the
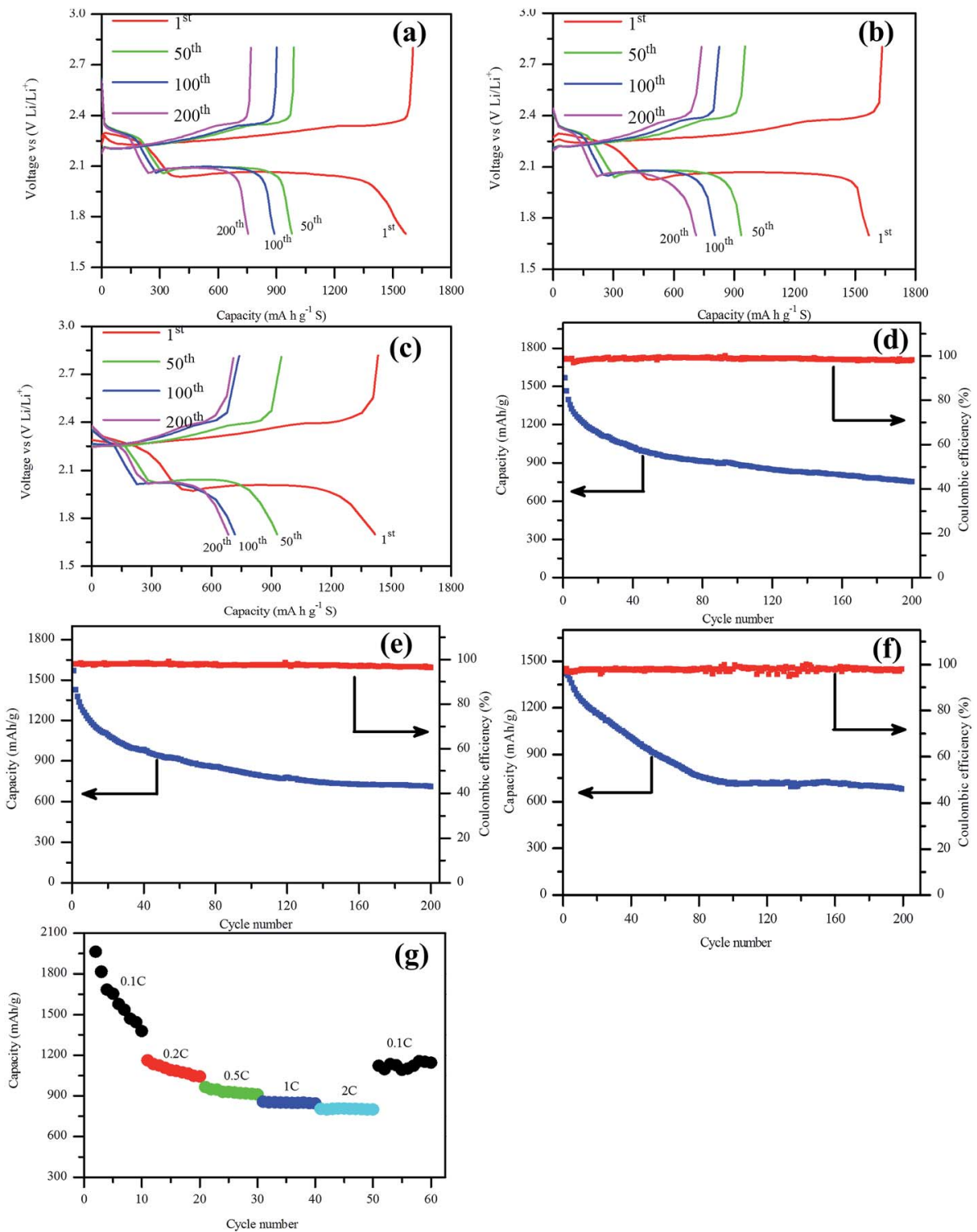

Fig. 5 Charge-discharge profiles of the battery at (a) $0.5 \mathrm{C}$ rate, (b) $1 \mathrm{C}$ rate, (c) $2 \mathrm{C}$ rate; the cycle performance of the batteries with current rate of (d) $0.5 \mathrm{C}$, (e) 1C, (f) 2C, and (g) rate capacity. 
desirable microstructure, affinitive heteroatoms from doping, and high electrical conductivity. The rate capacities of Li-S batteries at different current rates are compared in Fig. 5g. The NSG/S cathode exhibited excellent performance at different current densities. An initial discharge capacity of around 2268

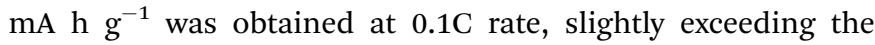
theoretical limit of Li-S battery due to the additional contribution from supercapacitor effect of graphene platelet. ${ }^{43,44}$ Some $\mathrm{Li}^{+}$ions may be stored reversibly between graphene planes, but the redox-based reversible storage should predominate, where the defects at edge sites or basal planes (vacancies and so on) of the NSG may be involved..$^{45}$ This high initial discharge capacity was followed by a sharp decrease in the following cycles and retained at $1378 \mathrm{~mA} \mathrm{~h} \mathrm{~g}^{-1}$ after 10 cycles. When the current density increased to $0.2 \mathrm{C}, 0.5 \mathrm{C}, 1 \mathrm{C}$, and $2 \mathrm{C}$ rate, the initial discharge capacity decreased to $1162,965,856$ and $803 \mathrm{~mA} \mathrm{~h} \mathrm{~g}^{-1}$ respectively. It can be seen that most of the battery capacity was retained with an increased current density to $2 \mathrm{C}$ rate, which can be partially attributed to the high electrical conductivity and easily accessible pores for $\mathrm{Li}^{+}$cations of the NSG/S composite. When the current rate was switched back to $0.1 \mathrm{C}$, a reversible capacity of $1122 \mathrm{~mA} \mathrm{~h} \mathrm{~g}^{-1}$ was achieved, confirming excellent electrode stability attributable to the encapsulate of polysulfides assisted by the nitrogen and sulfur containing functional groups after doping, and unique microstructure of this material.

The electrochemical performance of the NSG based cathodes was also evaluated using CV after cycling at 1C rate for 200 cycles (Fig. 6a) and after rate test from 0.1C to 2C (Fig. 6b) respectively. As shown in Fig. 7a, it displays two reduction peaks in the cathodic scan, which was related to the open ring reduction of sulfur $\left(\mathrm{S}_{8}\right)$ to the soluble lithium polysulfides $\left(\mathrm{Li}_{2} \mathrm{~S}_{x}, 4 \leq x \leq 8\right)$, and the reduction of higher order lithium polysulfides to $\mathrm{Li}_{2} \mathrm{~S}_{2}$ and $\mathrm{Li}_{2} \mathrm{~S} .{ }^{46,47}$ In the following potential sweeps, the anodic and cathodic curves overlapped, implying high reversibility of the electrode, which was consistent with the results at $0.5 \mathrm{C}$ as shown in Fig. S1a. $\dagger$ When the current density increased to 2C, the peak currents of oxidation and reduction increased with the increasing number of potential sweeps (Fig. S1b $\uparrow$ ). After the rate test, the potential difference decreased with the increasing potential sweeps (Fig. 6b), which indicated that the reversibility of electrode was enhanced with increasing potential cycles. Furthermore, there are two oxidation peaks after the first cycle, which may be related to the stepwise oxidation from $\mathrm{Li}_{2} \mathrm{~S} / \mathrm{Li}_{2} \mathrm{~S}_{2}$, through low and high order polysulfides, to the elemental sulfur. ${ }^{48,49}$ EIS measurement was conducted for the NSG/S based electrode before and after 200 charge-discharge cycles at $1 \mathrm{C}$ (Fig. $6 \mathrm{c}$ and $\mathrm{d}$ ) and $0.5 \mathrm{C}$ rate (Fig. S1d $\dagger$ ). From the Nyquist plot of EIS measurement, the charge-transfer resistances remained almost the same (9.4 and 8.4 $\Omega$ ) after cycling at 1C rate and rate cycling, which can be attributed to the stable structure of the NSG/S composite and a high electrical conductivity that can act as an efficient electron pathway at high current density. However, when the cathode was cycled for 200 times at $0.5 \mathrm{C}$ rate, the charge-transfer resistance $(31.2 \Omega$ ) inside the porous electrode and at SEI interface became much larger (Fig. S1d $\dagger$ ). The cycle stability of the cells at $1 \mathrm{C}$ and $2 \mathrm{C}$ with lower charge-transfer resistance was better than that at $0.5 \mathrm{C}$, which was consistent with the electrochemical test. After 200 cycles, the performance of the batteries at $0.5 \mathrm{C}$ was
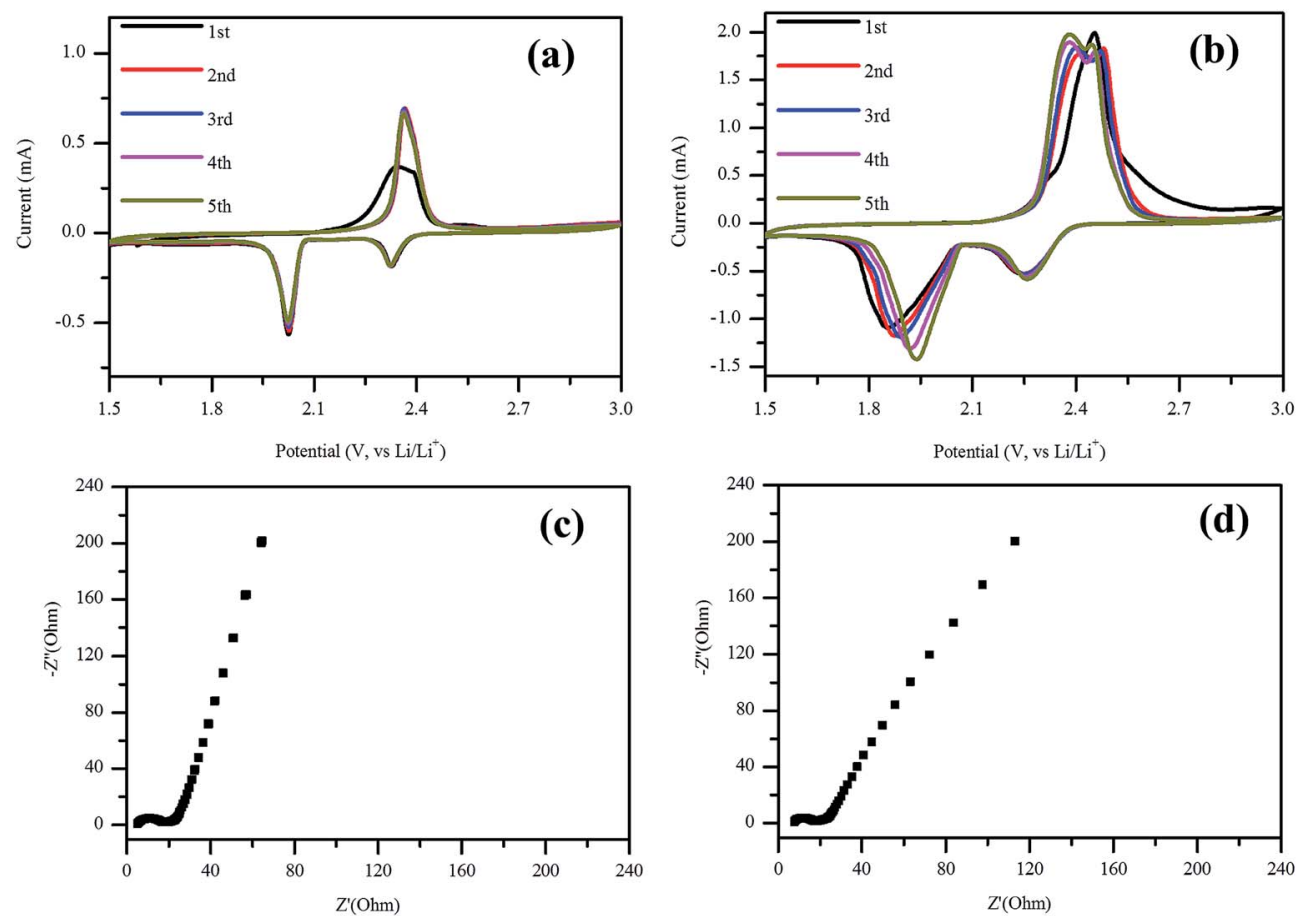

Fig. 6 CV of the cathode after (a) 200 cycles at 1C rate, (b) CV after rate cycles; electrochemical impedance spectroscopy plots of the cathode (c) after 200 cycles at $1 \mathrm{C}$ rate and (d) after rate cycles. 
worse than that of $1 \mathrm{C}$ and $2 \mathrm{C}$, which is in agreement with the high charge-transfer resistance at $0.5 \mathrm{C}$ rate.

In order to explore the affinitive interaction between heterogeneous dopant and sulfur or polysulfides, XPS analysis was conducted for the NSG/S composite before and after 200 cycles at $1 \mathrm{C}$ rate (Fig. 7a-d). In the survey spectrum of the NSG/S composite before cycling (Fig. 7a), the peaks located at 531.10, $399.70,284.40,227.50$, and $163.00 \mathrm{eV}$ corresponded to O $1 \mathrm{~s}, \mathrm{~N}$ $1 \mathrm{~s}, \mathrm{C} 1 \mathrm{~s}, \mathrm{~S} 2 \mathrm{~s}$, and S 2 p respectively, confirming the presence of $\mathrm{C}, \mathrm{O}, \mathrm{N}$, and $\mathrm{S}$ elements with atomic concentration of $86.33 \%$, $5.99 \%, 1.78 \%$, and $5.89 \%$ respectively. The C 1s spectrum exhibited two peaks at 284.92, and $285.70 \mathrm{eV}$, which can be ascribed to $\mathrm{sp}^{2}$ hybridized carbon ${ }^{50}\left(63.45\right.$ at\%) and $\mathrm{C}-\mathrm{S}$ bond ${ }^{51}$ (36.55 at\%) (Fig. 7b), implying the presence of strong covalent bonding between the NSG and sulfur. The N 1s spectrum of this composite can be deconvoluted into four peaks (Fig. 7c) at $398.44 \mathrm{eV}, 399.25 \mathrm{eV}, 401.64 \mathrm{eV}$, and $403.67 \mathrm{eV}$ originated from pyridinic-like $\mathrm{N}$ (6.41 at\%), pyrrolic-type $\mathrm{N}$ (5.20 at\%), graphitic $\mathrm{N}$ (79.76 at\%), and oxidized $\mathrm{N}$ species (8.63 at\%), respectively. Pyridinic $\mathrm{N}$ is known to influence the structure of graphene platelet and maintains a stable structure in the presence of monovacancy. ${ }^{52}$ The $\mathrm{sp}^{3}$ bonded pyrrolic $\mathrm{N}$ disrupted the planar structure of graphene platelet and dominated in the presence of Stone-Wales defect and divacancy defect. ${ }^{53,54}$ The $S 2 p$ peaks were characterized by a $S 2 \mathrm{p}^{3 / 2}$ and $2 \mathrm{p}^{1 / 2}$ doublet with an energy separation of $1.18 \mathrm{eV}$, reconfirming the presence of $\mathrm{C}-\mathrm{S}$ bonds ${ }^{50}$ (Fig. 7d). The mismatch of the outermost orbitals of S and C induces a non-uniform spin density distribution on S-doped graphene, which consequently endows graphene platelet preferable for electrocatalytic reactions ${ }^{55}$ because of the similar electronegativity of S (2.58) and C (2.55). ${ }^{56}$

After 200 cycles at $1 \mathrm{C}$ rate, the survey spectra of NSG/S composite revealed the presence of $\mathrm{C}, \mathrm{O}, \mathrm{N}$, and $\mathrm{S}$ elements, as well as F element (Fig. 7a) originated from the LiTFSI electrolyte and the PVDF binder. The $\mathrm{C} 1 \mathrm{~s}$ spectra were dominated by two peaks at 284.98 and $286.05 \mathrm{eV}$, corresponding to the $\mathrm{sp}^{2}$ hybridized carbon and carbon of $\mathrm{C}-\mathrm{S}$ nature, accompanied by four weak peaks at 288.69, 290.00, 290.82, and $293.35 \mathrm{eV}$, which can be ascribed to $\mathrm{C}=\mathrm{O}, \mathrm{C}-\mathrm{F}, \mathrm{CF}_{2} \mathrm{CH}_{2}$, and $\mathrm{C}_{10} \mathrm{~F}_{8}$ bonds respectively ${ }^{57-59}$ (Fig. 7b). Considering that the electrode was rinsed thoroughly with tetrahydrofuran to remove loosely bond LiTFSI electrolyte prior to XPS measurement, the presence of strong $\mathrm{F}$ 1s peak (10.06 at\%) and C-F component in C 1s peak indicated the passivation of NSG cathode by $\mathrm{F}$ containing electrolyte and PVDF binder, suggesting a polymeric surface passivation layer with TFSI anions and the decomposition of electrolyte during battery cycling. ${ }^{\mathbf{6 0 , 6 1}}$

The N 1s XPS spectra of the cathode changed noticeably compared with spectra acquired before cycling (Fig. 7c), which was originated from the $\mathrm{N}$ heteroatom and $\mathrm{LiNO}_{3}$ during the charge-discharge process. The peak components at 399.97, 401.49, and $404.13 \mathrm{eV}$ were ascribed to the pyrrolic-like $\mathrm{N}$, graphitic $\mathrm{N}$, and oxidized $\mathrm{N}$ respectively, with atomic concentration of $71.48 \%, 24.34 \%$, and $4.18 \%$ respectively. ${ }^{26}$ Pyridinic and pyrrolic $\mathrm{N}$ were formed at the defects sites, and these defects imposed a p-doping effect by withdrawing electrons
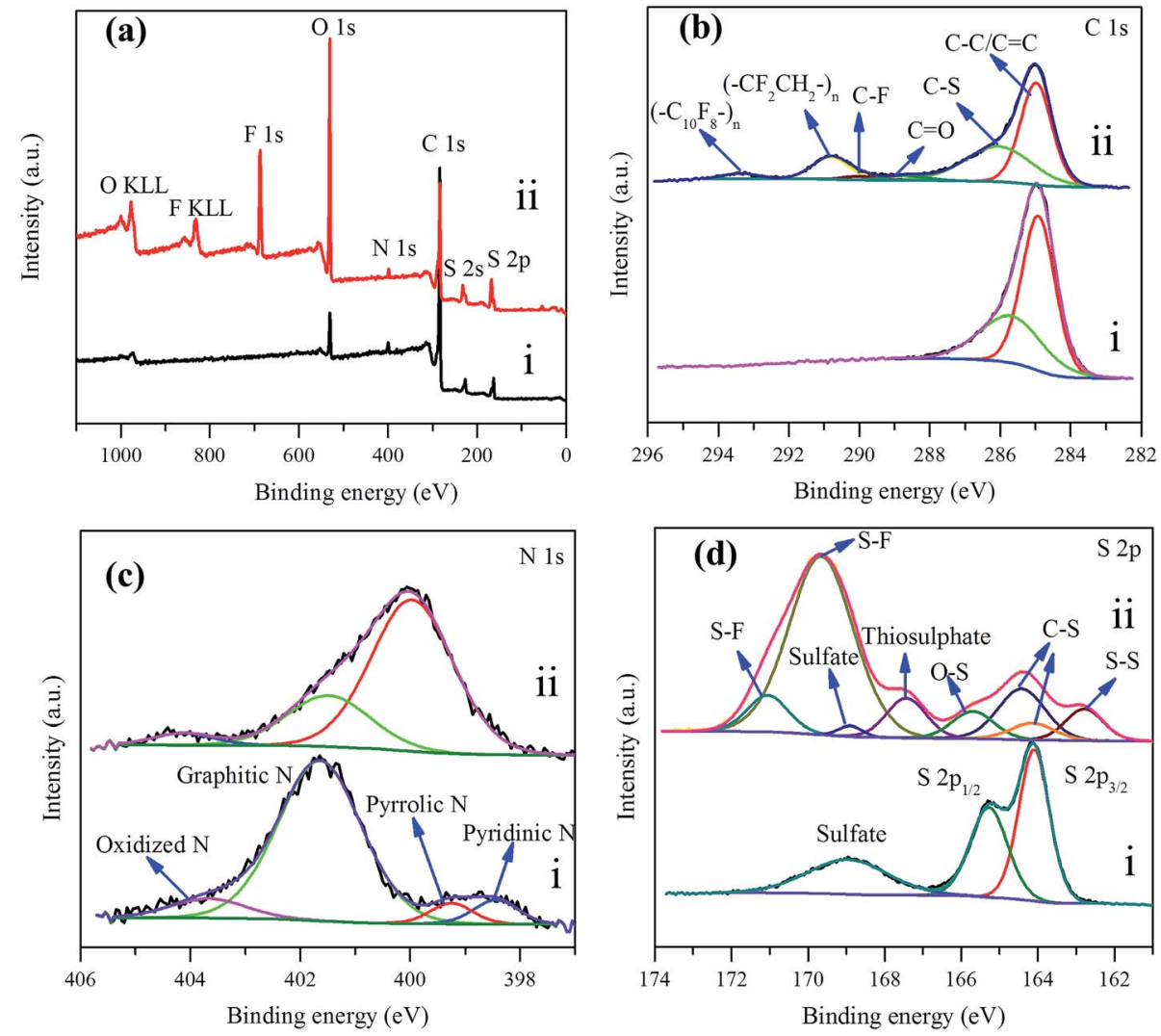

Fig. 7 (a) XPS survey spectrum of NSG/S composite (i) before and (ii) after 200 cycles at $1 \mathrm{C}$ rate, (b) C 1s, (c) N 1s, and (d) S 2p XPS spectra. 
from the graphene platelet, ${ }^{62}$ which was beneficial to immobilize polysulfide species to effectively enhance the electrochemical performance of sulfur cathodes. ${ }^{63,64}$ After 1C rate cycles, the pyridinic-type $\mathrm{N}$ became indiscernible and the content of pyrrolic-like $\mathrm{N}$ increased, indicating the transformation of pyridinic $\mathrm{N}$ to pyrrolic $\mathrm{N}$ during the chargedischarge processes which is in agreement with the high electrocatalytic activity of this configuration. In the meantime, the results implied that pyrrolic $\mathrm{N}$ was the most favorable $\mathrm{N}$ species for the adsorption of polysulfides during the electrochemical process. From the previous research, ${ }^{65}$ it could be seen that the pyridinic-like $\mathrm{N}$ had higher binding energy than the graphitic and oxidized $\mathrm{N}$, implied that pyridinic $\mathrm{N}$ significantly enhanced the interaction between the carbon host and the polysulfide guests and thereby effectively prevented the shuttling of polysulfides and improved the electrochemical performance of the batteries, which was consistent with the electrochemical test results. In addition, ameliorative deposition and recharging of $\mathrm{Li}_{2} \mathrm{~S}$ on the region of electron-rich pyridinic $\mathrm{N}$ were attributed to the favorable guest-host interaction at the electron-modified interface. ${ }^{66}$ Pyridinic N-dopants can strongly attract polysulfides with large enough binding energies to effectively anchor soluble polysulfides due to an enhanced attraction between $\mathrm{Li}$ ions in polysulfides and pyridinic N-dopants and/or an additional attraction between $\mathrm{S}$ anions in polysulfides and $\mathrm{Li}$ ions captured by pyridinic N-dopants. ${ }^{67}$ To investigate the affinitive interaction between pyrrolic $\mathrm{N}$ site and lithium polysulfides, $a b$ initio calculation was performed based on density functional theory (DFT). Three soluble polysulfides were used in the simulation $\left(\mathrm{Li}_{2} \mathrm{~S}_{x}, x=3,4,8\right)$, and they formed ring-like configuration with two $\mathrm{Li}^{+}$ions distributed on each side of the ring after optimization (Fig. 8) in consistent with the literature. ${ }^{68}$ The overall Mulliken charges of three nitrogen atoms at a pyrrolic nitrogen doped site were $-0.358,-0.418,-0.419$, much negative than the pyridinic (three nitrogen atoms with -0.249 ) and graphitic nitrogen (one nitrogen atom with $-0.476)$, indicating that pyrrolic nitrogen doped site imposed the strongest p-doping effect by withdrawing electrons from the graphene platelet. The isosurface of electron density map is also shown in Fig. 8, and the strongly negative charged pyrrolic $\mathrm{N}$ doped sites are believed to promote nucleophilic attraction to anchor $\mathrm{Li}_{2} \mathrm{~S}_{x}(x=3,4,8)$ by charge attraction with $\mathrm{Li}^{+}$. As the most soluble polysulfide, $\mathrm{Li}_{2} \mathrm{~S}_{8}$ was used to explore the adsorption strength with the heteroatoms. The interaction between $\mathrm{Li}_{2} \mathrm{~S}_{8}$ and pyrrolic $\mathrm{N}$ doped site was stronger than other configurations, in agreement with the literature. ${ }^{69}$

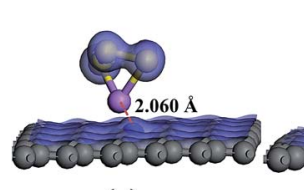

(a)

(c)

Fig. 8 Optimized adsorption structures and electron cloud distribution of (a) $\mathrm{Li}_{2} \mathrm{~S}_{3}$, (b) $\mathrm{Li}_{2} \mathrm{~S}_{4}$, and (c) $\mathrm{Li}_{2} \mathrm{~S}_{8}$ near the pyrrolic function on the graphene platelet.
A vastly different S 2p spectrum was also observed compared with the cathode before cycling (Fig. 7d). The peak at 162.79, 164.14, and $164.42 \mathrm{eV}$ corresponded to the S-S and C-S bonds, which can be assigned to sulfur atoms of C-S and S-S bond, ${ }^{20}$ the peak at $165.70 \mathrm{eV}$ corresponded to $\mathrm{O}-\mathrm{S}$ bond arising from the sulfate species formed by reaction with residual oxygen containing species during cycling, the peaks at 167.43 and $168.90 \mathrm{eV}$ can be assigned to the thiosulphate and sulfate, and the peaks at 169.65 and $171.05 \mathrm{eV}$ corresponded to the S-F bond ${ }^{70}$ where the F element originated from the electrolyte, indicating strong covalent interaction between $\mathrm{F}$ containing electrolyte and polysulfides on the NSG electrode. The results implied that some of the active S species had been transformed to thiosulphate during cycling. ${ }^{71}$ The thiosulphate can serve as a highly efficient polysulfide mediator to hinder the loss of lithium polysulfides from the cathode..$^{72}$ In summary, from the XPS spectra analysis, it can be seen that pyridinic-type $\mathrm{N}$, pyrrolic-like $\mathrm{N}$, and thiosulphate, originating from the amine and thiol groups in $\mathrm{L}$-cysteine, are the dominant factors contributing to the superior electrochemical performance of the NSG/S cathode (Fig. 1e).

\section{Conclusions}

In summary, we have developed a novel route to synthesize graphene platelet by in situ nitrogen and sulfur doping using $\mathrm{L}^{-}$ cysteine as carbon precursor. The synthesis process utilized $\mathrm{NaCl}$ salt as a template and structure directing agent that is non-toxic, easily manageable and can be processed at mild conditions. The prepared hybrid material possesses homogeneous and abundant active sites of heteroatoms via in situ doping, and a thin, flexible and highly conductive mesoporous structure was used as a sulfur host that facilitated the electron transfer and provided easily accessible pores for lithium ions. This unique structure promoted the confinement of lithium polysulfides on the cathode surface and enhanced the discharge capacity of the NSG/S composite in Li-S batteries especially at high rate. This NSG/S composite material exhibited a highly reversible discharge capacity (initial discharge capacity of around $1635 \mathrm{~mA} \mathrm{~h} \mathrm{~g}^{-1}$ at $1 \mathrm{C}$ ) and outstanding performance at high current density ( $684 \mathrm{~mA} \mathrm{~h} \mathrm{~g}{ }^{-1}$ after 200 cycles at $2 \mathrm{C}$ ). The novel template synthesis method, in situ doping by special precursor using water soluble crystals in this study and the understanding of the electrode surface chemistry during charging and discharging will inspire the design of novel electrode materials for high performance $\mathrm{Li}-\mathrm{S}$ batteries.

\section{Acknowledgements}

The authors would like acknowledge the financial supports from National Program on Key Basic Research of China (973 Program, 2015CB258400), the National Thousand Young Talents Program, Natural Science Foundation of China (51508213, 51608217, 21607046), Key project of Hubei Provincial Natural Science Foundation (2014CFA109), General program of Natural Science Foundation of Hubei Province (ZRMS2016000433), Innovative and Interdisciplinary Team at HUST (0118261077) and Independent Innovation Foundation of 
HUST-Exploration Fund (2016YXMS288, 2014TS092). The authors would like to thank the Analytical and Testing Center of Huazhong University of Science and Technology for providing the facilities to fulfill the experimental measurements, especially Mr Jinjin Wu's assistant with SEM measurement.

\section{Notes and references}

1 S. W. Kim, D. H. Seo, X. Ma, G. Ceder and K. Kang, Adv. Eng. Mater., 2012, 2, 710-721.

2 R. Younesi, G. M. Veith, P. Johansson, K. Edström and T. Vegge, Energy Environ. Sci., 2015, 8, 1905-1922.

3 V. Etacheri, R. Marom, R. Elazari, G. Salitra and D. Aurbach, Energy Environ. Sci., 2011, 4, 3243.

4 L. Ma, K. E. Hendrickson, S. Wei and L. A. Archer, Nano Today, 2015, 10, 315-338.

5 J. G. Wang, K. Xie and B. Wei, Nano Energy, 2015, 15, 413444.

6 G. Li, H. Jing, H. Li, L. Liu, Y. Wang, C. Yuan, H. Jiang and L. Chen, Ionics, 2015, 21, 2161-2170.

7 J. Ma, Z. Fang, Y. Yan, Z. Yang, L. Gu, Y.-S. Hu, H. Li, Z. Wang and X. Huang, Adv. Eng. Mater., 2015, 5, 1500046.

8 N. Jayaprakash, J. Shen, S. S. Moganty, A. Corona and L. A. Archer, Angew. Chem., Int. Ed., 2011, 50, 5904-5908.

9 Y. Yang, G. Zheng and Y. Cui, Chem. Soc. Rev., 2013, 42, 30183032.

10 Z. Li, Y. Huang, L. Yuan, Z. Hao and Y. Huang, Carbon, 2015, 92, 41-63.

11 L. Sun, D. Wang, Y. Luo, K. Wang, W. Kong, Y. Wu, L. Zhang, K. Jiang, Q. Li, Y. Zhang, J. Wang and S. Fan, ACS Nano, 2016, 10, 1300-1308.

12 S. Dorfler, M. Hagen, H. Althues, J. Tubke, S. Kaskel and M. J. Hoffmann, Chem. Commun., 2012, 48, 4097-4099.

13 V. A. Agubra, L. Zuniga, D. Flores, J. Villareal and M. Alcoutlabi, Electrochim. Acta, 2016, 192, 529-550.

14 Z. Li, S. Zhang, C. Zhang, K. Ueno, T. Yasuda, R. Tatara, K. Dokko and M. Watanabe, Nanoscale, 2015, 7, 1438514392.

15 W. Choi, I. Lahiri, R. Seelaboyina and Y. S. Kang, Crit. Rev. Solid State Mater. Sci., 2010, 35, 52-71.

16 R. J. Young, I. A. Kinloch, L. Gong and K. S. Novoselov, Compos. Sci. Technol., 2012, 72, 1459-1476.

17 V. Chabot, D. Higgins, A. Yu, X. Xiao, Z. Chen and J. Zhang, Energy Environ. Sci., 2014, 7, 1564.

18 J. L. Shi, C. Tang, H. J. Peng, L. Zhu, X. B. Cheng, J. Q. Huang, W. Zhu and Q. Zhang, Small, 2015, 11, 5243-5252.

19 L. Zhang, H. Huang, H. Yin, Y. Xia, J. Luo, C. Liang, Y. Gan, X. Tao and W. Zhang, J. Mater. Chem. A, 2015, 3, 1651316519.

20 S. Yuan, Z. Guo, L. Wang, S. Hu, Y. Wang and Y. Xia, Adv. Sci., 2015, 2, 1500071.

21 S. Niu, W. Lv, C. Zhang, Y. Shi, J. Zhao, B. Li, Q.-H. Yang and F. Kang, J. Power Sources, 2015, 295, 182-189.

22 S. Liu, K. Xie, Z. Chen, Y. Li, X. Hong, J. Xu, L. Zhou, J. Yuan and C. Zheng, J. Mater. Chem. A, 2015, 3, 11395-11402.

23 M. Guo, J. Huang, X. Kong, H. Peng, H. Shui, F. Qian, L. Zhu, W. Zhu and Q. Zhang, New Carbon Mater., 2016, 31, 352-362.
24 J. Song, M. L. Gordin, T. Xu, S. Chen, Z. Yu, H. Sohn, J. Lu, Y. Ren, Y. Duan and D. Wang, Angew. Chem., Int. Ed., 2015, 54, 4325-4329.

25 S. Zhang, Inorg. Chem. Front., 2015, 2, 1059-1069.

26 J. Zhang, Y. Cai, Q. Zhong, D. Lai and J. Yao, Nanoscale, 2015, 7, 17791-17797.

27 Y. Xie, Z. Meng, T. Cai and W. Q. Han, ACS Appl. Mater. Interfaces, 2015, 7, 25202-25210.

28 F. Wu, J. Li, Y. Tian, Y. Su, J. Wang, W. Yang, N. Li, S. Chen and L. Bao, Sci. Rep., 2015, 5, 13340.

29 S. Niu, W. Lv, G. Zhou, Y. He, B. Li, Q. H. Yang and F. Kang, Chem. Commun., 2015, 51, 17720-17723.

30 Y. Cao, X. L. Li, M. S. Zheng, M. P. Yang, X. L. Yang and Q. F. Dong, Electrochim. Acta, 2016, 192, 467-474.

31 L. Chen, Z. Chen, Z. Huang, Y. Wang, H. Zhou and Y. Kuang, New J. Chem., 2015, 39, 8901-8907.

32 G. Qu, J. Cheng, X. Li, L. Huang, W. Ni, Z. Wang and B. Wang, ACS Appl. Mater. Interfaces, 2015, 7, 16668-16675.

33 G. Hu, C. Xu, Z. Sun, S. Wang, H. M. Cheng, F. Li and W. Ren, Adv. Mater., 2016, 28, 1603-1609.

34 L. Fei, X. Li, W. Bi, Z. Zhuo, W. Wei, L. Sun, W. Lu, X. Wu, K. Xie, C. Wu, H. L. Chan and Y. Wang, Adv. Mater., 2015, 27, 5936-5942.

35 Z. Zhang, G. Wang, Y. Lai, J. Li, Z. Zhang and W. Chen, J. Power Sources, 2015, 300, 157-163.

36 J. Xiao, H. Wang, X. Li, Z. Wang, J. Ma and H. Zhao, J. Mater. Sci.: Mater. Electron., 2015, 26, 7895-7900.

37 Z. Li and L. Yin, Nanoscale, 2015, 7, 9597-9606.

38 R. Ansari, S. Sahmani and B. Arash, Phys. Lett. A, 2010, 375, 53-62.

39 F. Tuinstra, J. Chem. Phys., 1970, 53, 1126.

40 T. Bordjiba, M. Mohamedi and L. H. Dao, J. Power Sources, 2007, 172, 991-998.

41 Z. Zhang, Z. Li, F. Hao, X. Wang, Q. Li, Y. Qi, R. Fan and L. Yin, Adv. Funct. Mater., 2014, 24, 2500-2509.

42 H. Xu, L. Qie and A. Manthiram, Nano Energy, 2016, 26, 224232.

43 L. Zhang, X. Zhao, M. D. Stoller, Y. Zhu, H. Ji, S. Murali, Y. Wu, S. Perales, B. Clevenger and R. S. Ruoff, Nano Lett., 2012, 12, 1806-1812.

44 Z. Gao, J. Wang, Z. Li, W. Yang, B. Wang, M. Hou, Y. He, Q. Liu, T. Mann, P. Yang, M. Zhang and L. Liu, Chem. Mater., 2011, 23, 3509-3516.

45 L. H. Hu, F. Y. Wu, C. T. Lin, A. N. Khlobystov and L. J. Li, Nat. Commun., 2013, 4, 1687.

46 G. Zhou, L. Li, D. W. Wang, X. Y. Shan, S. Pei, F. Li and H. M. Cheng, Adv. Mater., 2015, 27, 641-647.

47 J. Wang, Y. S. He and J. Yang, Adv. Mater., 2015, 27, 569-575. 48 J. Conder, A. Forner-Cuenca, E. M. Gubler, L. Gubler, P. Novak and S. Trabesinger, ACS Appl. Mater. Interfaces, 2016, 8, 18822-18831.

49 X. Zhou, J. Xie, J. Yang, Y. Zou, J. Tang, S. Wang, L. Ma and Q. Liao, J. Power Sources, 2013, 243, 993-1000.

50 G. Li, J. Sun, W. Hou, S. Jiang, Y. Huang and J. Geng, Nat. Commun., 2016, 7, 10601.

51 Z. Wang, Y. Dong, H. Li, Z. Zhao, H. B. Wu, C. Hao, S. Liu, J. Qiu and X. W. Lou, Nat. Commun., 2014, 5, 5002. 
52 X. Wang, G. Sun, P. Routh, D. H. Kim, W. Huang and P. Chen, Chem. Soc. Rev., 2014, 43, 7067.

53 Z. Hou, X. Wang, T. Ikeda, K. Terakura, M. Oshima and M.-a. Kakimoto, Phys. Rev. B: Condens. Matter Mater. Phys., 2013, 87, 165401.

54 T. Schiros, D. Nordlund, L. Palova, D. Prezzi, L. Zhao, K. S. Kim, U. Wurstbauer, C. Gutierrez, D. Delongchamp, C. Jaye, D. Fischer, H. Ogasawara, L. G. Pettersson, D. R. Reichman, P. Kim, M. S. Hybertsen and A. N. Pasupathy, Nano Lett., 2012, 12, 4025.

55 J. Liang, Y. Jiao, M. Jaroniec and S. Z. Qiao, Angew. Chem., Int. Ed., 2012, 51, 11496.

56 S. Glenis, A. J. Nelson and M. M. Labes, J. Appl. Phys., 1999, 86, 4464.

57 M. Ackeret, Surf. Sci. Spectra, 1992, 1, 108.

58 S. C. Yoon and B. D. Ratner, Macromolecules, 1986, 19, 10681079.

59 H. S. Munro and C. Till, J. Polym. Sci., Part A: Polym. Chem., 1987, 25, 1065-1071.

60 S. A. Delp, O. Borodin, M. Olguin, C. G. Eisner, J. L. Allen and T. R. Jow, Electrochim. Acta, 2016, 209, 498-510.

61 D. Ensling, M. Stjerndahl, A. Nytén, T. Gustafsson and J. O. Thomas, J. Mater. Chem., 2009, 19, 82-88.

62 Z. Wang, Y. Dong, H. Li, Z. Zhao, H. B. Wu, C. Hao, S. Liu, J. Qiu and X. W. Lou, Nat. Commun., 2014, 5, 5002.
63 K. Han, J. Shen, S. Hao, H. Ye, C. Wolverton, M. C. Kung and H. H. Kung, ChemSusChem, 2014, 7, 2545-2553.

64 M. Yu, R. Li, Y. Tong, Y. Li, C. Li, J. D. Hong and G. Q. Shi, J. Mater. Chem. A, 2015, 3, 9609-9615.

65 T. Z. Hou, X. Chen, H. J. Peng, J. Q. Huang, B. Q. Li, Q. Zhang and B. Li, Small, 2016, 12, 3283-3291.

66 H. J. Peng, T. Z. Hou, Q. Zhang, J. Q. Huang, X. B. Cheng, M. Q. Guo, Z. Yuan, L. Y. He and F. Wei, Adv. Mater. Interfaces, 2014, 1, 1400227.

67 L. C. Yin, J. Liang, G. M. Zhou, F. Li, R. Saito and H. M. Cheng, Nano Energy, 2016, 25, 203-210.

68 Z. Ji, B. Han, Q. Li, C. Zhou, Q. Gao, K. Xia and J. Wu, J. Phys. Chem. C, 2015, 119, 20495-20502.

69 J. Balach, H. K. Singh, S. Gomoll, T. Jaumann, M. Klose, S. Oswald, M. Richter, J. Eckert and L. Giebeler, ACS Appl. Mater. Interfaces, 2016, 8, 14586-14595.

70 B. J. Lindberg, K. Hamrin, G. Johansson, U. Gelius, A. Fahlman, C. Nordling and K. Siegbahn, Phys. Scr., 1970, 1, 286.

71 X. Feng, M. K. Song, W. C. Stolte, D. Gardenghi, D. Zhang, X. Sun, J. Zhu, E. J. Cairns and J. Guo, Phys. Chem. Chem. Phys., 2014, 16, 16931-16940.

72 X. Liang, C. Hart, Q. Pang, A. Garsuch, T. Weiss and L. F. Nazar, Nat. Commun., 2015, 6, 5682. 